\title{
Use of magnetic nanoparticles as a drug delivery system to improve chlorhexidine antimicrobial activity
}

\author{
Grażyna Tokajuk ${ }^{1,2}$ \\ Katarzyna Niemirowicz' \\ Piotr Deptuła ${ }^{1,3}$ \\ Ewelina Piktel' \\ Mateusz Cieśluk' \\ Agnieszka Z Wilczewska ${ }^{4}$ \\ Jan R Dąbrowski \\ Robert Bucki \\ 'Department of Microbiological \\ and Nanobiomedical Engineering, \\ Medical University of Białystok, \\ ${ }^{2}$ Department of Intergrated Dentistry, \\ Medical University of Białystok, \\ ${ }^{3}$ Department of Materials and \\ Biomedical Engineering, Białystok \\ University of Technology, ${ }^{4}$ Institute \\ of Chemistry, University of Białystok, \\ Białystok, Poland
}

This article was published in the following Dove Press journal:

International Journal of Nanomedicine

25 October 2017

Number of times this article has been viewed
Abstract: Nanotechnology offers new tools for developing therapies to prevent and treat oral infections, particularly biofilm-dependent disorders, such as dental plaques and endodontic and periodontal diseases. Chlorhexidine (CHX) is a well-characterized antiseptic agent used in dentistry with broad spectrum activity. However, its application is limited due to inactivation in body fluid and cytotoxicity toward human cells, particularly at high concentrations. To overcome these limitations, we synthesized nanosystems composed of aminosilane-coated magnetic nanoparticles functionalized with chlorhexidine (MNP@CHX). In the presence of human saliva, MNPs@, CHX displayed significantly greater bactericidal and fungicidal activity against planktonic and biofilm-forming microorganisms than free CHX. In addition, CHX attached to MNPs has an increased ability to restrict the growth of mixed-species biofilms compared to free CHX. The observed depolarization of mitochondria in fungal cells treated with MNP@CHX suggests that induction of oxidative stress and oxidation of fungal structures may be a part of the mechanism responsible for pathogen killing. Nanoparticles functionalized by CHX did not affect host cell proliferation or their ability to release the proinflammatory cytokine, IL-8. The use of MNPs as a carrier of CHX has great potential for the development of antiseptic nanosystems.

Keywords: chlorhexidine, magnetic nanoparticles, antimicrobial properties, anti-biofilm

\section{Introduction}

Chlorhexidine ( $\mathrm{CHX})$ is a biguanide derivative with broad antimicrobial activity against bacteria, fungi and viruses. ${ }^{1-3}$ It targets compounds such as lipopolysaccharide and lipoteichoic acid on the microorganism membrane, ${ }^{4,5}$ and at low concentrations $\mathrm{CHX}$ affects membrane integrity, while at higher concentrations it causes the cytoplasm to congeal. Previously published data indicate that $\mathrm{CHX}$ may be toxic to mammalian cells. ${ }^{6} \mathrm{CHX}$ is one of the most frequently used antiseptics in medicine, particularly in dentistry and surgery. ${ }^{7-9}$ It is used for the treatment and prevention of gingivitis and periodontitis, and as agents for the treatment of wounds or burns. ${ }^{10-13}$ The antimicrobial activity of $\mathrm{CHX}$ is $\mathrm{pH}$ sensitive and the optimal $\mathrm{pH}$ value is $\sim 7.0 .{ }^{14}$ Furthermore, its antimicrobial activity is reduced in the presence of serum, plasma, pus and other organic material, such as surfactants and anionic polyelectrolytes. ${ }^{1,14,15}$ Interestingly, recent data suggest that certain Gram-negative bacterial isolates are able to grow in the presence of $1 \% \mathrm{CHX} .{ }^{16}$ It has also been noted that $\mathrm{CHX}$ is responsible for the induction of VanA-type vancomycin resistance genes in Enterococcus species. ${ }^{17}$ In addition, Liu et al demonstrated the increasing prevalence of CHX-tolerant high-level mupirocin-resistant, methicillin-resistant Staphylococcus aureus (MRSA) strains. ${ }^{18}$ Taken together, these observations suggest that the use of CHX may be limited in
Correspondence: Robert Bucki

Department of Microbiological and Nanobiomedical Engineering, Medical University of Białystok, Mickiewicza 2c, 15-222 Białystok, Poland

Tel +48 857485483

$\mathrm{Fax}+48857485434$

Email buckirobert@gmail.com
International Journal of Nanomedicine 2017:12 7833-7846

7833 
certain settings and may require higher doses to obtain the desired therapeutic effects. An emerging therapeutic strategy is the use of nanoparticles as drug carriers. ${ }^{19,20}$ Studies show that the immobilization/encapsulation process improves the overall biological effectiveness of active agents including pharmacokinetic parameters (bioavailability, clearance) and reduces the side effects. ${ }^{21-23}$ In addition, it has been noted that the antibiotic resistance of drug-resistant pathogens may be overcome by using nanoparticles as antibiotic carriers. ${ }^{24}$ Among the many types of nanostructures, core-shell magnetic iron oxide nanoparticles are the most commonly used drug carriers in biomedical studies. ${ }^{20,25}$ Due to their unique properties (size, magnetic moment, surface properties), the use of magnetic nanomaterials (MNPs) may represent a new approach for the treatment of infections caused by drugresistant pathogens. These nanoparticles are able to interact with planktonic bacteria as well as those embedded in a biofilm matrix..$^{26,27}$ The general mechanism of nanoparticle toxicity against pathogens involves binding to the cell wall and subsequent disruption of the membrane through either direct interaction and/or oxidation of macromolecules. ${ }^{28}$ Interestingly, recent reports indicate that metal-oxide nanoparticles are nontoxic to mammalian cells due to their ability to phagocytose and degrade nanoparticles through lysosomal fusion. ${ }^{28}$ These properties allow treatment with nanoparticles to maintain normal cell function while also restricting the processes that promote pathogen growth and infection development. These properties govern nanomaterial selectivity to enhance tissue-forming cell function, while also restricting pathogen growth and viability that are responsible for infection development. Our previous studies indicate that the immobilization of ceragenin on the MNP surface increases its antibacterial activity in the presence of body fluids. ${ }^{22}$ In addition, recent work suggests that the application of nanosystems composed of MNPs and polyene antibiotic may be used for the treatment of infections caused by polyeneresistant fungal strain. ${ }^{29}$ In the present study, we evaluate the activity of magnetic nanosystems functionalized with chlorhexidine against clinical isolates of pathogens from different groups including representatives of Gram-positive and Gram-negative bacteria and fungal cells. We demonstrate that covalent attachment of $\mathrm{CHX}$ on the magnetic carrier improves their antimicrobial activity compared to a nonimmobilized agent in conditions that mimic the oral cavity environment. Importantly, these nanosystems are characterized by lower cytotoxic effects on dental osteoblasts indicating enhanced biocompatibility. Furthermore, CHX-functionalized nanoparticles did not affect cell proliferation or the ability to release IL-8 from human osteoblast cells.

\section{Materials and methods Synthesis of magnetic nanoparticles functionalized by $\mathrm{CHX}$}

The magnetic core was synthesized using a well-known modification of the Massart method, which is based on the coprecipitation of hydrated iron chloride salts under treatment by ammonium hydroxide (25\%). ${ }^{25,30}$ Stöber methods were used to obtain core-shell magnetic nanostructures with terminal propylamine groups. ${ }^{26,31}$ Immobilization of CHX onto the surface of nanoparticles was achieved by interaction between the primary amine group of nanoparticles and the chloride group from CHX. After anchoring, the precipitate was magnetically collected, washed with ethanol and phosphate-buffered saline (PBS) and dried at $50^{\circ} \mathrm{C}$.

\section{Nanoparticle characterization}

Fourier transform infrared spectroscopy (FTIR) spectra were recorded using the Thermo Fisher Scientific Nicolet iN10 MX FTIR microscope. A $10 \mu \mathrm{L}$ sample $(1 \mathrm{mg} / \mathrm{mL})$ was dropped on the surface of a glossy metal plate, and the solvent was left to evaporate. All spectra were collected in the $4,000-800 \mathrm{~cm}^{-1}$ range by co-adding 64 scans with a resolution of $4 \mathrm{~cm}^{-1}$. Data analysis was performed using OMNIC software (Thermo Fisher Scientific). UV-VIS spectra were recorded using Thermo Fisher Scientific Varioskan LUX. The absorbance spectra $(200-400 \mathrm{~nm})$ of a $100 \mu \mathrm{L}$ sample $(1 \mathrm{mg} / \mathrm{mL})$ were registered. A METTLER TOLEDO DSC 1 STAR system was used to perform differential scanning calorimetry (DSC). Nitrogen was used as a purge gas $(10 \mathrm{~mL} / \mathrm{min})$. Samples $(2 \mathrm{mg})$ were placed in aluminum pans and heated from $25^{\circ} \mathrm{C}$ to $450^{\circ} \mathrm{C}$ with a heating rate of $20^{\circ} \mathrm{C} / \mathrm{min}$. Thermogravimetric analysis (TGA) was recorded using a Mettler Toledo Star TGA/DSC unit. Nanoparticles $(2 \mathrm{mg})$ were placed in the aluminum pans $(40 \mu \mathrm{L})$ and heated from $50^{\circ} \mathrm{C}$ to $900^{\circ} \mathrm{C}$ with a heating rate of $10^{\circ} \mathrm{C} / \mathrm{min}$. Magnetic properties of the tested nanoparticles were determined using a Quantum Design MPMS 5XL SQUID-type magnetometer; the samples were prepared as described previously. ${ }^{32}$ The morphology of MNP@CHX was studied using transmission electron microscopy (TEM; Tecnai G2 X-TWIN). Samples for TEM were prepared by solvent evaporation from nanoparticle dispersion on holey carbon copper grids.

\section{Determination of minimum inhibitory concentration (MIC)/minimal fungicidal concentration (MFC)/minimal biofilm inhibitory concentration (MBIC) values}

The MIC and minimal bactericidal concentration (MBC) or MFC were determined using pathogens at the logarithmic 
phase of growth. All experiments were performed using CHX and MNP@CHX at a concentration range of $32-0.125 \mu \mathrm{g} / \mathrm{mL}$. The activity of the tested agents was evaluated against representatives of Gram-positive bacteria such as MRSA, methicillin-sensitive Staphylococcus aureus (MSSA) and Enterococcus faecalis, and Gram-negative bacteria such as Escherichia coli (ESBL) and Pseudomonas aeruginosa Xen 5 (MDR) and fungal Candida sp. laboratory strains and clinical isolates $\left(\sim 10^{3} \mathrm{CFU} / \mathrm{mL}\right)$. The microbial identification was performed using VITEK ${ }^{\circledR}$ 2 SYSTEM (bioMérieux). The MIC/MBC or MFC values were determined using the microdilution method. An MTT assay was performed to evaluate the MBIC. ${ }^{33}$ The MIC values were determined visually as the lowest concentration of tested antimicrobial agents that inhibit pathogen growth. MBC or MFC was performed by spotting treated samples of microbial cells on Luria-Bertani (LB) agar or Sabouraud dextrose agar plates. To evaluate the impact of saliva on the antimicrobial activity of CHX and MNP@ $\mathrm{CHX}$, the MIC/MFC/MBIC values were determined in the presence of $50 \%$ saliva. The chemiluminescent intensity of $P$. aeruginosa Xen5 $\left(\mathrm{OD}_{600}=0.5\right)$ following treatment with CHX/MNP@CHX in the presence or absence of saliva was measured as an additional method to assess bacterial viability.

\section{Anti-biofilm assay}

To evaluate the inhibitory activity of tested agents against biofilm formation, cells $\left(\sim 10^{6} \mathrm{CFU} / \mathrm{mL}\right)$ were grown for $48 \mathrm{~h}$ at $37^{\circ} \mathrm{C}$ in the presence or absence of CHX or MNP@CHX in the concentration range of $0.5-50 \mu \mathrm{g} / \mathrm{mL}$ in LB liquid medium. After incubation, the biofilm was washed four times with $100 \mu \mathrm{L}$ PBS to remove planktonic nonadherent cells. Crystal violet (CV) staining $(0.1 \%)$ was used to determine the total biofilm mass. The viability of cells embedded in the biofilm matrix was performed using an MTT assay and by CFU determination via spotting on an agar plate. Measurement of OD to evaluate biofilm mass (CV) and cell viability (MTT) was performed using Varioskan LUX. The positive control was pathogen growth without the presence of tested agents, while the negative control was empty well without bacteria/fungal cells..$^{34,35}$

\section{Determination of oxidative stress}

Oxidative stress was analyzed using a Mitochondrial Potential Kit and the NucleoCounter ${ }^{\circledR}$ NC-3000 ${ }^{\mathrm{TM}}$ system following the manufacturer's instructions. Fungal cells stained with JC-1/DAPI were immediately loaded into an NCSlide. Mitochondrial depolarization was calculated as a decrease in the red/green fluorescence intensity ratio. Necrotic and late apoptotic cells were detected as blue fluorescent DAPI stained cells.

\section{Cell culture}

Human osteoblast cells hFOB 1.19 were purchased from American Type Culture Collection (Manassas, Virginia, USA) and maintained in a 1:1 mixture of Ham's F12 Medium Dulbecco's Modified Eagle's Medium, with $2.5 \mathrm{mM}$ L-glutamine, without phenol red, supplemented with $10 \%$ fetal bovine serum, $50 \mathrm{U} / \mathrm{mL}$ penicillin, $50 \mathrm{mg} / \mathrm{mL}$ streptomycin and $0.3 \mathrm{mg} / \mathrm{mL}$ G418 in a humidified incubator containing $5 \% \mathrm{CO}_{2}$ in air at $34^{\circ} \mathrm{C}$.

\section{Evaluation of IL-8 concentration and cytotoxicity using hFOB I.19 cell line}

To evaluate interleukin-8 (IL-8) release and cytotoxicity after CHX and MNP@CHX addition, cells were seeded at a density of $2 \times 10^{4}$ cells per well in $1 \mathrm{~mL}$ of growth medium in 24-well plates. After $24 \mathrm{~h}$ of culture, cells were treated with the tested agents at a concentration range of $1-150 \mu \mathrm{g} / \mathrm{mL}$. After $24 \mathrm{~h}$ incubation, an IL-8 and LDH assay was performed. The average of all the experiments is shown as the percentage of cell viability compared to control, while cells treated with lytic solution were considered as $100 \% \mathrm{LDH}$ release. IL-8 concentration was determined using an IL-8 ELISA kit (Invitrogen).

\section{Proliferation assay}

To assess the effect of free CHX or immobilized on the magnetic nanoparticles, hFOB 1.19 cells proliferation was assessed. Cells were seeded in 96-well plates at $2 \times 10^{4}$ cells/well with $100 \mu \mathrm{L}$ of growth medium. Then the tested agents were added to subconfluent cells at a concentration range of $5-250 \mu \mathrm{g} / \mathrm{mL}$. After $24 \mathrm{~h}$ incubation at $34^{\circ} \mathrm{C}$, resazurin $(5 \mu \mathrm{g} / \mathrm{mL})$ was added and fluorescence was recorded for $6 \mathrm{~h}$ with excitation/emission wavelengths of $520 / 590 \mathrm{~nm}$.

\section{Ethics statement}

To perform the evaluation of tested agents in the presence of saliva, the materials were collected under IRB protocol: R-I-002/575/2013. This study was approved by the institutional review board (IRB) of the Medical University of Białystok. For both studies, all subjects provided informed written consent and collected samples were anonymous. 


\section{Results}

\section{Nanoparticle characterization}

The synthesized chlorhexidine-coated magnetic nanoparticles (MNP@CHX) were characterized by FTIR spectroscopy. Figure 1A shows FTIR spectra for CHX in free
(CHX) and immobilized form-MNP@CHX. The presence of the aminosilane shell around the magnetic core is indicated by a broad band at $\sim 1,038-1,249 \mathrm{~cm}^{-1}$ corresponding to $\mathrm{Si}-\mathrm{O}$, $\mathrm{Si}-\mathrm{O}-\mathrm{Si}$ and $\mathrm{Fe}-\mathrm{O}-\mathrm{Si}$ stretching vibrations. In both samples, the bands at 3,355 and 3,393 $\mathrm{cm}^{-1}$ correspond to $\mathrm{N}-\mathrm{H}$ bending
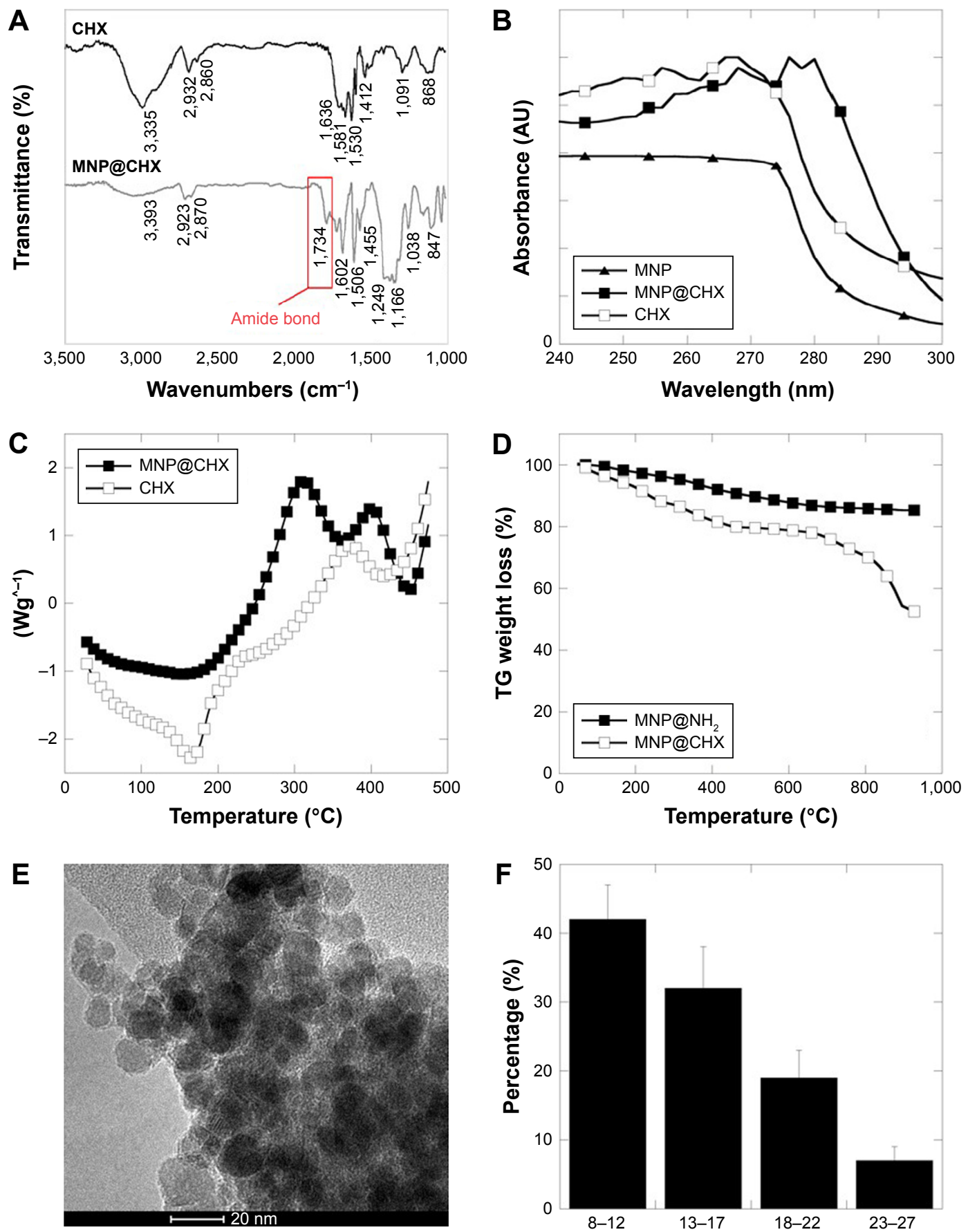

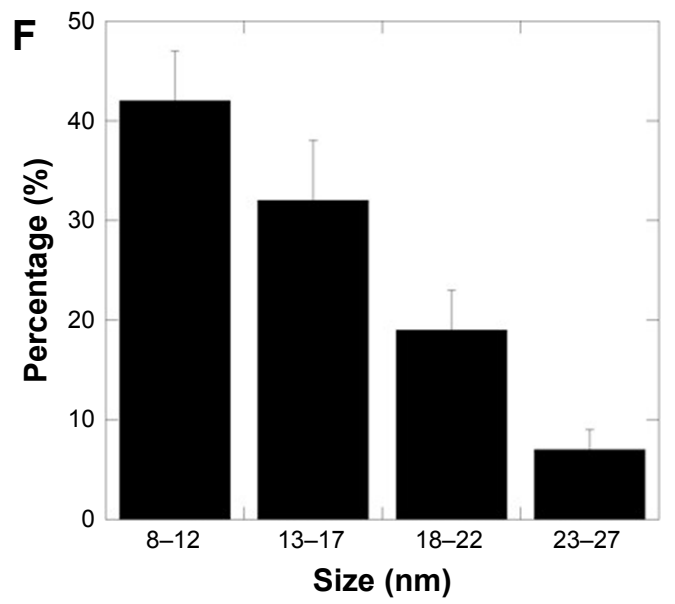

Figure I Physicochemical properties of chlorhexidine-coated magnetic nanoparticles.

Notes: ATR FTIR spectra of the CHX and MNP@CHX (A). The UV-VIS spectra of uncoated MNP, MNP@CHX and free CHX (B). The DSC thermographs of CHX and MNP@CHX (C). Thermogravimetric analysis curves of magnetic nanoparticles coated by aminosilane and MNP@CHX (D). Transmission electron microscopy images (E) and size distribution (F) of MNP@CHX.

Abbreviations: ATR, attenuated total reflectance; CHX, chlorhexidine; DSC, differential scanning calorimetry; FTIR, Fourier transform infrared spectroscopy; MNP, magnetic nanoparticles; MNP@CHX, MNP functionalized by chlorhexidine; TG, thermogravimetric; UV-VIS, ultraviolet-visible. 
and stretching vibrations, respectively. Bonds registered at $1,530-1,581 \mathrm{~cm}^{-1}$ have been assigned for the $\mathrm{NH}_{2}$ inplane deformation vibration. The weak signals observed at $868 \mathrm{~cm}^{-1}$ for CHX and at $847 \mathrm{~cm}^{-1}$ from MNP@CHX are due to $\mathrm{NH}$ wagging. Strong adsorption bonds around $1,600 \mathrm{~cm}^{-1}$ might be ascribed to $\mathrm{C}=\mathrm{N}$ stretching vibration which is characteristic for biguanide derivatives. After functionalization with $\mathrm{CHX}$, a stretching vibration of the $\mathrm{C}=\mathrm{O}$ bond around $1,734 \mathrm{~cm}^{-1}$ was recorded. The occurrence of $\mathrm{C}-\mathrm{H}$ stretching bonds around 2,900 $\mathrm{cm}^{-1}$ was associated with symmetric and asymmetric ethyl and alkyl groups, which confirm the existence of an aminosilane shell on the MNP surface and the presence of CHX. UV-VIS spectroscopy was used to confirm successful functionalization of the nanoparticle surface. The absorbance spectra were obtained for aminosilane-coated MNPs (filled triangles) before functionalization. The similarity between the $\mathrm{CHX}$ curves (empty squares) and $\mathrm{CHX}$ functionalized nanocarriers MNP@CHX (filled squares) registered at specific for biguanide region (255-275 nm) strongly supports our results that $\mathrm{CHX}$ was successfully attached to the nanoparticle surface (Figure 1B).

The thermal properties of synthesized nanoparticles were characterized by DSC (Figure 1C). The heating curves of free CHX (empty squares) and MNP@CHX (filled squares) indicate similarity in the chemical nature of the tested compounds. The decomposition of the organic skeleton at temperatures higher than $150^{\circ} \mathrm{C}$ was observed in the DSC curve of both agents. However, a weaker effect was observed for MNP@ $\mathrm{CHX}$. In both cases, large exothermic peaks were found around $370^{\circ} \mathrm{C}-400^{\circ} \mathrm{C}$. Figure $1 \mathrm{D}$ shows the thermogravimetric analysis of the aminosilane- and CHX-decorated MNPs, respectively. In accordance with previously published results, a $6 \%-8 \%$ weight loss was observed for bare MNPs in the temperature range of $50^{\circ} \mathrm{C}-800^{\circ} \mathrm{C}$, which is ascribed to the removal of adsorbed water and decomposition of hydroxyl surface groups. ${ }^{36}$ The thermogravimetric analysis curves for aminosilane-coated MNPs (filled squares) show that the weight loss is about $9 \%$ (Figure 1D). The thermogravimetric analysis of CHX-functionalized MNPs (empty squares) shows a weight loss around $40 \%$ compared to the weight loss recorded for bare and aminosilane-coated MNPs. This indicates successful CHX immobilization on the MNP surface, with $\sim 40 \%$ yield.

The analysis of saturation magnetization value of tested nanoparticles indicated a value of 68.7 emu/g for MNP@ CHX. A relatively narrow size distribution of magnetic nanoparticles functionalized with CHX showed that MNP@ CHX was characterized by spherical shape with a diameter of $12 \pm 2 \mathrm{~nm}$ as determined from the TEM image (the size was calculated using 100 randomly selected particles; Figure 1E and F). In comparison with previously characterized aminosilane-coated MNPs, the obtained size of CHX-decorated MNPs did not significantly differ. ${ }^{37}$

\section{Covalent immobilization of $\mathrm{CHX}$ increases antimicrobial properties and enhances activity in the presence of saliva}

In order to evaluate the antimicrobial potential of the synthesized derivative, $\mathrm{MIC} / \mathrm{MBC}$ or $\mathrm{MFC} / \mathrm{MBIC}$ values of $\mathrm{CHX}$ and MNP@CHX against bacterial and fungal pathogens were assessed. As shown in Table 1, the functionalization of $\mathrm{CHX}$ onto the MNP surface strongly enhances the killing effect of $\mathrm{CHX}$ against all the tested strains. We observed a significant decrease in MIC/MBC or MFC/MBIC concentrations from 2 to 32 times. In the case of activity of magnetic nanocarriers, their activity against all tested strains was $>32 \mu \mathrm{g} / \mathrm{mL}$. Importantly, this trend is preserved in the presence of human saliva (Table 2). It is noteworthy that covalent immobilization of CHX on the MNPs not only increases the antimicrobial properties of $\mathrm{CHX}$ against individual bacterial and fungal strains but is also effective against samples containing mixed bacterial and fungal pathogens. Reduction of biofilm formation, particularly those formed by mixed species in conditions mimicking the oral cavity, is important for the creation of multimode antimicrobial agents. The preventive

Table I MIC $(\mu \mathrm{g} / \mathrm{mL})$ and MBC/MFC $(\mu \mathrm{g} / \mathrm{mL})$ of $\mathrm{CHX}$ and MNP@CHX against different pathogens including different clinical isolated from oral cavity/throat*

\begin{tabular}{|c|c|c|c|}
\hline Strain & $\begin{array}{l}\text { Pathogen } \\
\text { source }\end{array}$ & $\begin{array}{l}\text { CHX } \\
\text { MIC/MBC or } \\
\text { MFC/MBIC }\end{array}$ & $\begin{array}{l}\text { MNP@CHX } \\
\text { MIC/MBC or } \\
\text { MFC/MBIC }\end{array}$ \\
\hline $\begin{array}{l}\text { Staphylococcus } \\
\text { aureus (MRSA) }\end{array}$ & Laboratory strain & $16 / 16 / 32$ & $4 / 8 / 16$ \\
\hline $\begin{array}{l}\text { Staphylococcus } \\
\text { aureus (MSSA) }\end{array}$ & Laboratory strain & $16 / 16 / 32$ & $4 / 4 / 16$ \\
\hline Enterococcus faecalis & Surgery wound & $\mid 6 / 32 />32$ & $8 / 16 / 32$ \\
\hline Escherichia coli & Surgery wound & $8 / 16 />32$ & $0.25 / 1 / 2$ \\
\hline $\begin{array}{l}\text { Pseudomonas } \\
\text { aeruginosa }\end{array}$ & Laboratory strain & $32 />32 />32$ & $|6 / 32|>32$ \\
\hline Candida albicans & Laboratory strain & $\mid 6 / 32 />32$ & $2 / 4 / 8$ \\
\hline Candida albicans* & Oral swabs & $|6 / 32|>32$ & $8 / 8 / 8$ \\
\hline Candida albicans* & Oral swabs & $16 / 16 / 16$ & $2 / 2 / 2$ \\
\hline Candida albicans* & Throat swabs & $4 / 8 / 8$ & $4 / 4 / 4$ \\
\hline Candida glabrata* & Throat swabs & $8 / 16 / 32$ & $4 / 4 / 8$ \\
\hline Candida tropicalis* & Oral swabs & $4 / 8 / 8$ & $4 / 4 / 4$ \\
\hline
\end{tabular}

Note: *Indicates clinical isolates from oral cavity/throat.

Abbreviations: $\mathrm{CHX}$, chlorhexidine; $\mathrm{MBC}$, minimal bactericidal concentration; MBIC, minimal biofilm inhibitory concentration; MFC, minimal fungicidal concentration; MIC, minimal inhibitory concentration; MNP@CHX, magnetic nanoparticles functionalized by chlorhexidine; MRSA, methicillin-resistant Staphylococcus aureus; MSSA, methicillin-sensitive Staphylococcus aureus. 
Table 2 MIC $(\mu \mathrm{g} / \mathrm{mL})$ and MBC/MFC $(\mu \mathrm{g} / \mathrm{mL})$ of $\mathrm{CHX}$ and MNP@CHX against different pathogens in the presence of human saliva

\begin{tabular}{|c|c|c|}
\hline \multirow[t]{2}{*}{ Strain } & $\mathrm{CHX}$ & MNP@CHX \\
\hline & $\begin{array}{l}\text { MIC/MBC or } \\
\text { MFC/MBIC }\end{array}$ & $\begin{array}{l}\text { MIC/MBC or } \\
\text { MFC/MBIC }\end{array}$ \\
\hline Staphylococcus aureus (MRSA) & $32 />32 />32$ & $16 / 16 / 32$ \\
\hline Enterococcus faecalis & $16 / 32 />32$ & $16 / 16 / 32$ \\
\hline Pseudomonas aeruginosa & $4 / 16 / 32$ & $4 / 4 / 8$ \\
\hline Candida albicans & $16 / 16 / 32$ & $4 / 4 / 4$ \\
\hline C. albicans + S. aureus & $32 / 32 />32$ & $8 / 16 / 16$ \\
\hline C. albicans + E. faecalis & $32 />32 />32$ & $16 / 16 / 32$ \\
\hline C. albicans $+P$. aeruginosa & $32 />32 />32$ & $8 / 16 / 16$ \\
\hline
\end{tabular}

Abbreviations: $\mathrm{CHX}$, chlorhexidine; $\mathrm{MBC}$, minimal bactericidal concentration; MBIC, minimal biofilm inhibitory concentration; MFC, minimal fungicidal concentration; MIC, minimal inhibitory concentration; MNP@CHX, magnetic nanoparticles functionalized by chlorhexidine; MRSA, methicillin-resistant Staphylococcus aureus.

activities of CHX and MNP@CHX against biofilms representative of Gram-positive and Gram-negative bacteria and fungi are shown in Figure 2. Functionalization of $\mathrm{CHX}$ to the MNP surface enhanced bactericidal activity two times in dosage range from 0.5 to $20 \mu \mathrm{g} / \mathrm{mL}$ for $S$. aureus, E. coli and C. albicans (Figure 2A, D, and E). Furthermore, compared to $\mathrm{CHX}, \mathrm{MNP} @ \mathrm{CHX}$ restricted biofilm formation by $>50 \%$ (Figure $2 \mathrm{~A}$ and $\mathrm{C}$ ). Functionalization of $\mathrm{CHX}$ does not improve efficacy against all tested strains; similar activity of CHX and MNP@CHX were observed against E. faecalis biofilm formation (Figure 2B). We then tested the activity of $\mathrm{CHX}$ and $\mathrm{MNP} @ \mathrm{CHX}$ in the presence of human saliva, conditions designed to mimic the oral cavity. For all tested species, human saliva impaired the activity of free CHX (Figure 3). However, this effect was not observed for MNP@CHX. We observed two- to sixfold enhanced inhibition of biofilm formation after addition of MNP@ CHX at concentrations from 1 to $50 \mu \mathrm{g} / \mathrm{mL}$ (Figure $3 \mathrm{~A}-\mathrm{D}$ ). Additionally, data in Figure 3E-G suggest that MNP@CHX has an increased ability to restrict growth of mixed-species biofilms compared to nonimmobilized agents. When $\mathrm{CHX}$ is covalently immobilized on the surface of MNPs, the growth of pathogenic cells is inhibited two times in all conditions (Figure 3E-G). The ability of the tested agents to inhibit fungal biofilm formation was further demonstrated in the
A Staphylococcus aureus (MRSA)

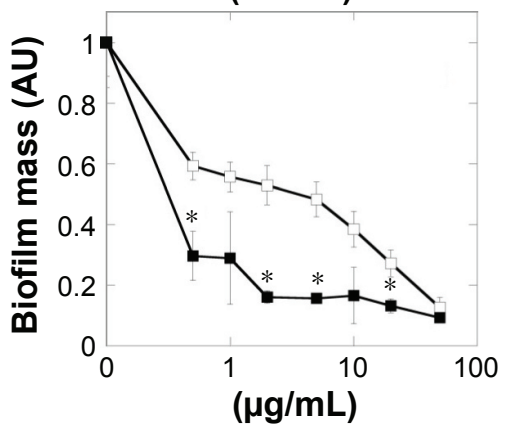

B

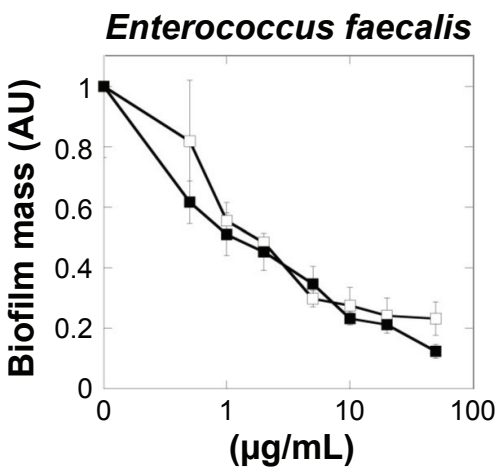

C

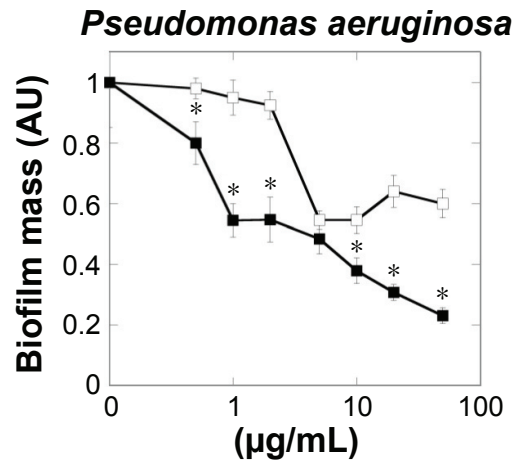

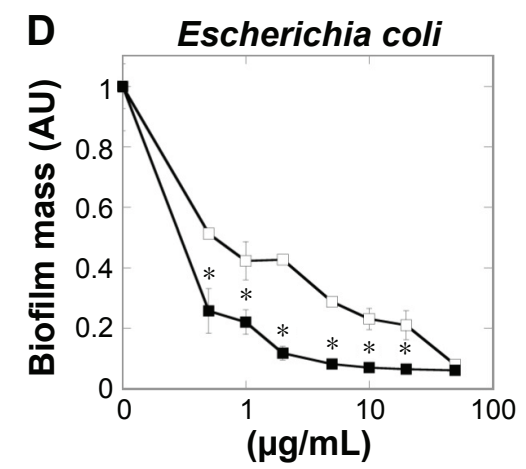

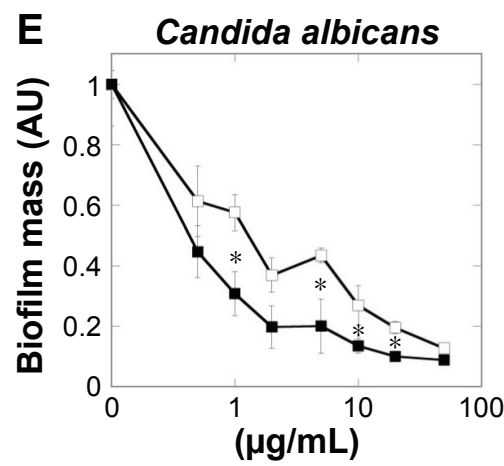

$\longrightarrow-\mathrm{CHX} \longrightarrow-\mathrm{MNP} @ \mathrm{CHX}$

Figure 2 Anti-biofilm activity of chlorhexidine-coated magnetic nanoparticles against different biofilm-forming pathogens.

Notes: (A-E) Preventive effect of free CHX and MNP@CHX against biofilm-forming representative of Gram-positive and Gram-negative bacteria and fungi. *Statistically significant $(P \leq 0.05)$ activity of MNP@CHX compared to $\mathrm{CHX}$.

Abbreviations: $\mathrm{CHX}$, chlorhexidine; MNP@CHX, magnetic nanoparticles functionalized by chlorhexidine; MRSA, methicillin-resistant Staphylococcus aureus. 
A Staphylococcus aureus (MRSA)

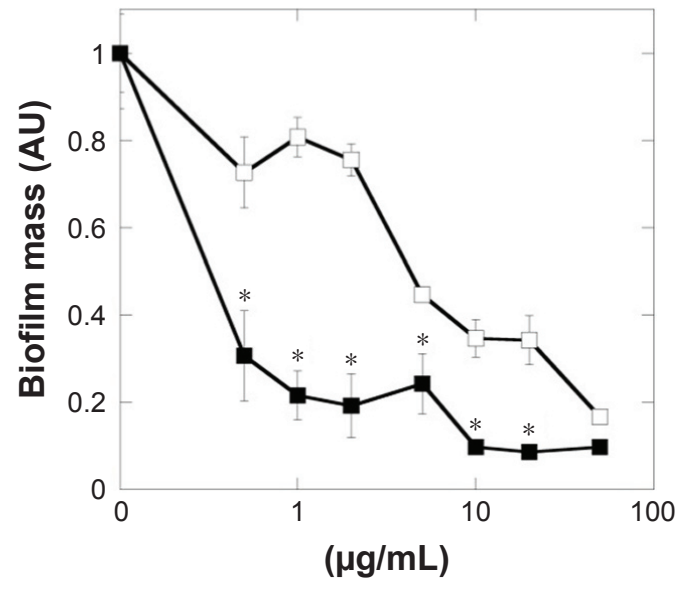

\section{B Pseudomonas aeruginosa}

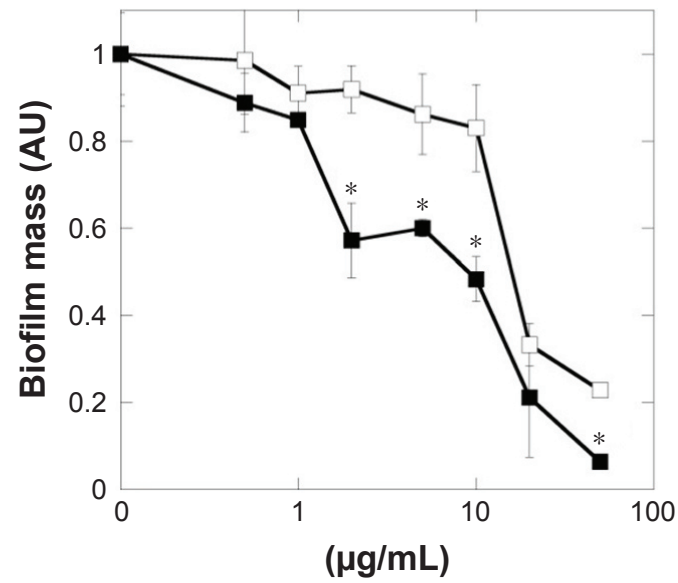

$\square-\mathrm{CHX} \rightarrow-\mathrm{MNP} @ \mathrm{CHX}$

C

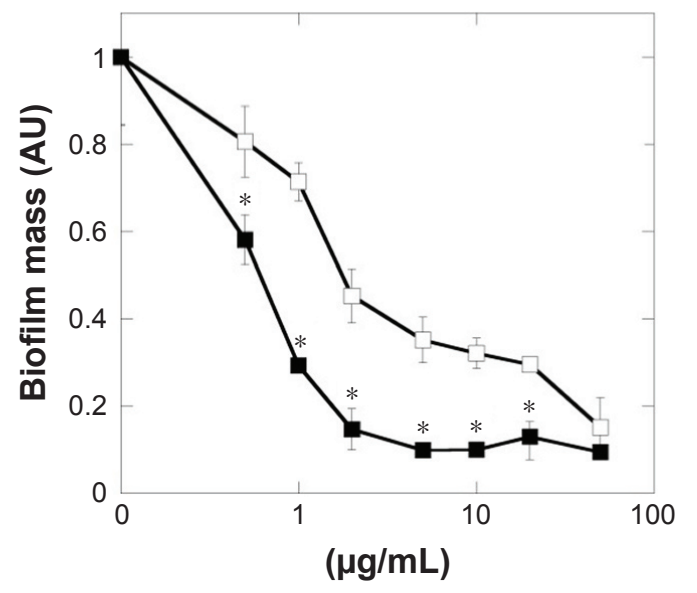

D Candida albicans

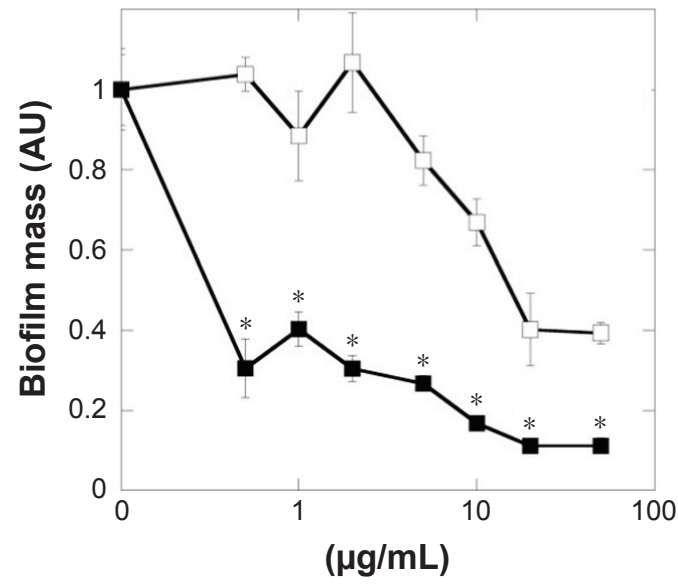

$\rightarrow \mathrm{CHX} \rightarrow-\mathrm{MNP@CHX}$

E

C. albicans + S. aureus

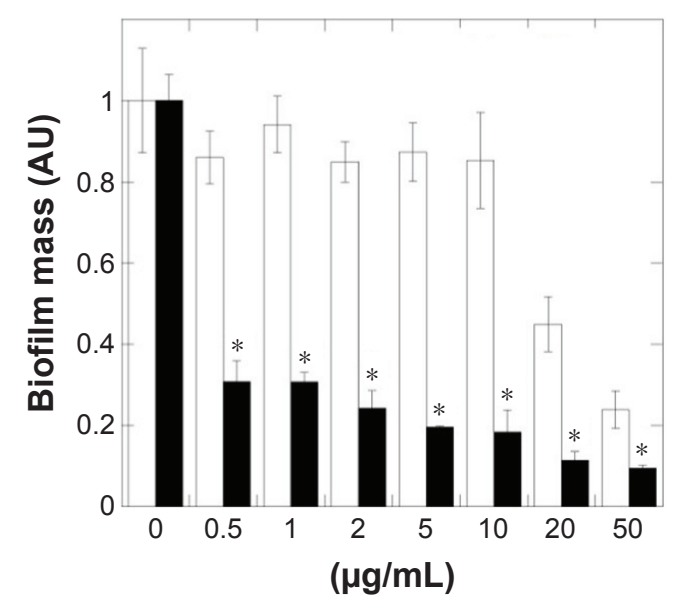

$\mathbf{F}$

C. albicans $+P$. aeruginosa

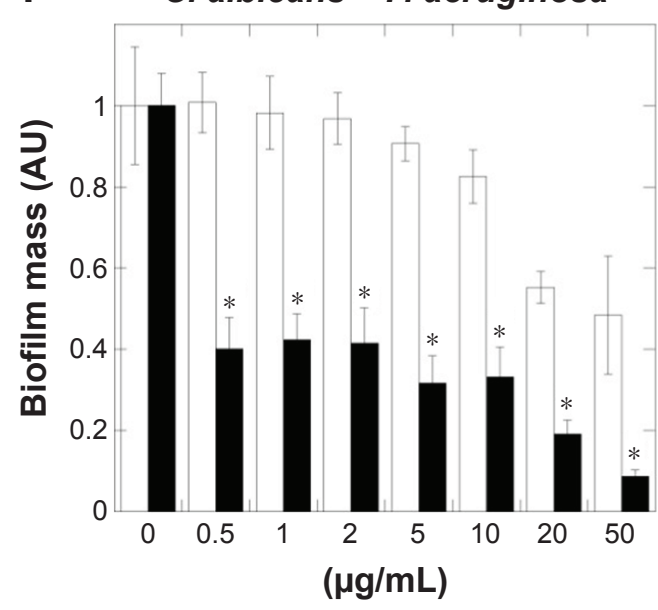

$\mathrm{CHX}$ MNP@CHX 


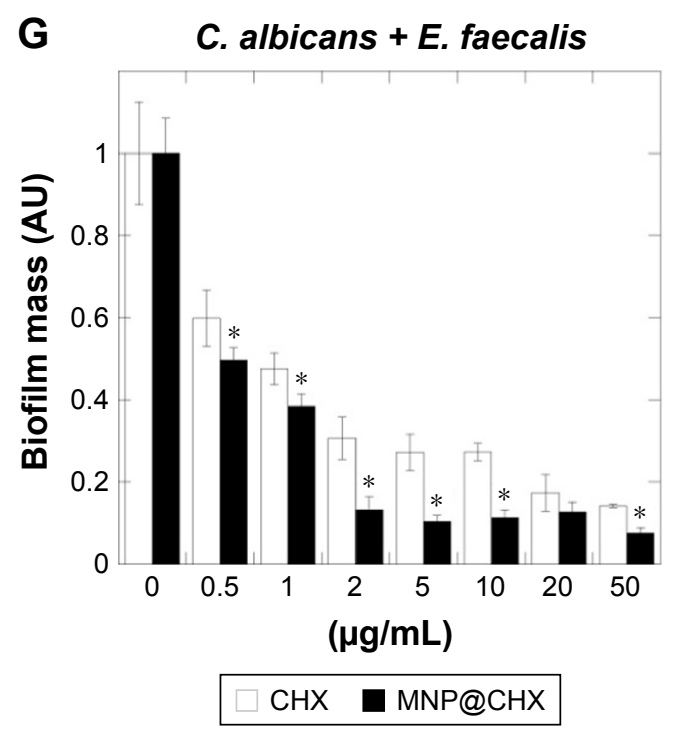

Figure 3 Magnetic nanoparticles increase anti-biofilm activity of chlorhexidine in the presence of human saliva.

Notes: Preventive activity of free CHX and MNP@CHX against biofilm-forming pathogens in the presence of human saliva (A-D). Effective inhibition of mixed-species biofilm formation in the presence of human saliva $(\mathbf{E}-\mathbf{G})$. *Statistically significant $(P \leq 0.05)$ activity of magnetic nanoparticles coated by chlorhexidine compared to nonimmobilized drugs. Abbreviations: $\mathrm{CHX}$, chlorhexidine; MNP@CHX, magnetic nanoparticles functionalized by chlorhexidine; MRSA, methicillin-resistant Staphylococcus aureus.

presence of human saliva (Figure 4). Biofilm mass as well as biofilm viability on the surface of dental fillings were reduced by twofold after the addition of CHX and fourfold following the addition of MNP@CHX. The aforementioned results were further confirmed by microtomography (Figure 4). A similar result was obtained in the case of acryl substrate (data not shown).

\section{Magnetic nanoparticles modify $\mathrm{CHX}$ mode of action}

As shown in Figure 5, the treatment of Candida cells by magnetic derivatives of $\mathrm{CHX}$ caused $\sim 15 \%$ increase in mitochondrial damage compared to free drug (Figure 5C and D). The level of oxidative stress induced by MNP@CHX is comparable to that caused by hydrogen peroxide (Figure 5B and D). Moreover, luminomeric analysis indicates that MNP@CHX inhibit the metabolic activity of bacterial cells by twofold (Figure 6A). In addition, data in Figure 6B show that the presence of human saliva significantly decreases CHX metabolic effects while the effects of MNP@CHX remain unchanged.

\section{Magnetic nanoparticles increase biocompatibility of $\mathrm{CHX}$ toward human osteoblast cells}

The lytic activities of the pure agents, bare magnetic nanocarrier and tested nanosystem on hFOB 1.19 cells are shown in Figure 7A. Application of nanosystems at concentrations from 1 to $50 \mu \mathrm{g} / \mathrm{mL}$ did not disrupt osteoblast membranes.
In comparison with MNP@CHX, bare nanocarriers and free CHX induced significantly toxic effects. As shown in Figure 7B, the tested agents caused IL-8 release from human osteoblast cells at concentration ranges similar to those required for effective pathogen killing and prevention of biofilm formation. Data in Figure $7 \mathrm{C}-\mathrm{F}$ demonstrate that compared to control CHX exerts high inhibition effect on hFOB 1.19 cell proliferation. The twofold decrease of cell proliferation was also observed after the addition of bare and CHX-decorated carriers at $250 \mu \mathrm{g} / \mathrm{mL}$. Notably, treatment of cells with MNP@CHX did not affect cell proliferation at the concentration range of $5-150 \mu \mathrm{g} / \mathrm{mL}$.

\section{Discussion}

In recent years, inorganic metallic-based core-shell nanomaterials, especially those composed of an iron oxide core, have emerged as drug delivery systems with unique properties, such as the easier synthesis, the ability for drug loading, release of their cargo in a specified manner as well as improved biocompatibility. In addition, iron oxide magnetic nanomaterials are able to disrupt pathogen membranes and generate reactive oxygen species, which cause mitochondrial damage. These beneficial features support the application of magnetic nanomaterials as a drug carrier in modern therapies. The number of infections caused by drug-resistant pathogens is constantly growing; it is estimated that patients with MDR strains have $>60 \%$ mortality compared to those with nonresistant infections. A consequence of increasing drug resistance is persistence of infection with increased risk of 
A

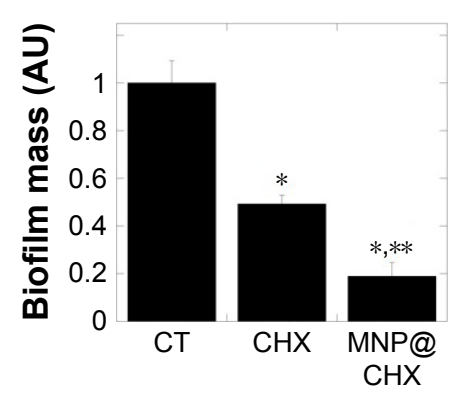

B

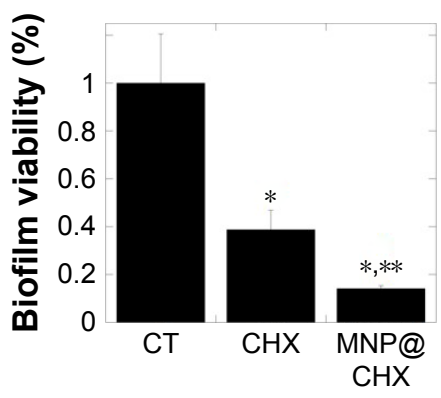

C

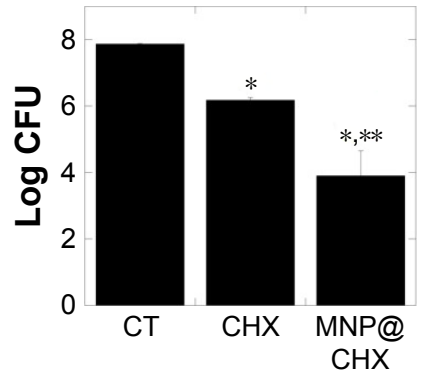

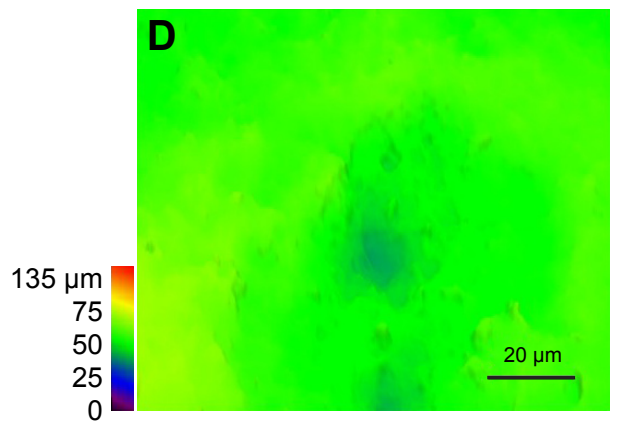
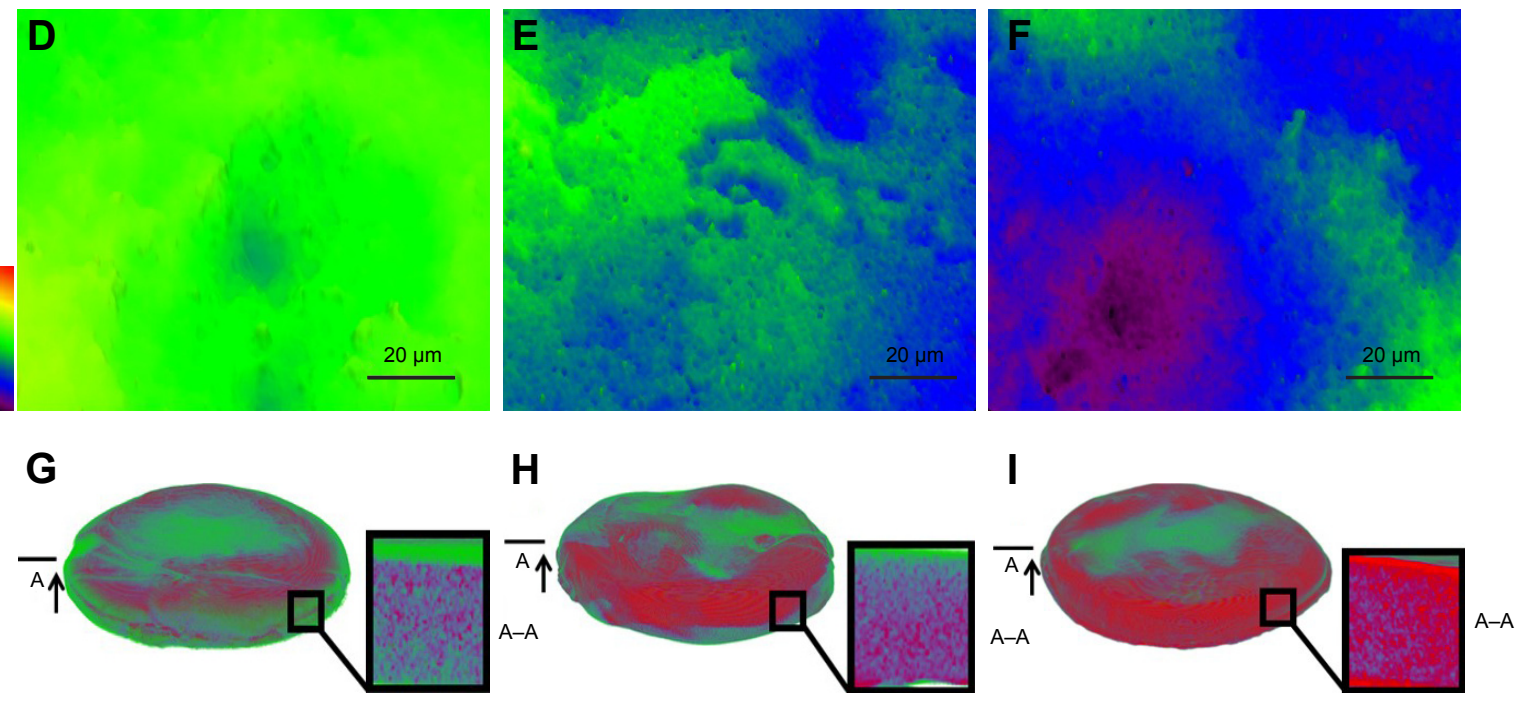

Figure 4 Chlorhexidine in free and immobilized form activity against fungal biofilm formation on the surface of dental filling.

Notes: Reduction of biofilm mass $(\mathbf{A})$ and cell viability $(\mathbf{B}, \mathbf{C})$ after addition of $\mathrm{CHX}$ and MNP@CHX at $20 \mu \mathrm{g} / \mathrm{mL}$. Panels $(\mathbf{E}$ and $\mathbf{F})$ represent effective restriction of biofilm formation during $72 \mathrm{~h}$ on the surface of dental fillings after addition of chlorhexidine and MNP@CHX at $20 \mu \mathrm{g} / \mathrm{mL}$ compared to control (D). X-ray microtomography 3D images and cross sections of dental fillings with mature fungal biofilm before $(\mathbf{G})$ and after treatment by chlorhexidine $(\mathbf{H})$ and $\mathrm{MNP} @ \mathrm{CHX}(\mathbf{I})$ at $20 \mu \mathrm{g} / \mathrm{mL}$. *Statistically significant $(P \leq 0.05)$ activity tested agents compared to untreated control $(C T)$. **Statistically significant $(P \leq 0.05)$ activity of magnetic nanoparticles coated by chlorhexidine compared to nonimmobilized drugs. Red color indicates dental filling; green color shows the presence of fungal biofilm. The "A"s, arrows, and line segments indicate the place of cutting of material (technical drawing); the "A-A"s indicate cross-section of material.

Abbreviations: CFU, colony forming units; CHX, chlorhexidine; MNP@CHX, magnetic nanoparticles functionalized by chlorhexidine.

spread. Development of resistance is directly associated with the ability of pathogens to form biofilms. Biofilm formation usually exhibits resistance to classical antibiotic treatment, which is conditioned by an increase of total macromolecules contents of the biofilm matrix. ${ }^{38,39}$ In effect, nanotechnologybased therapies may be promising in the eradication of bacterial and fungal pathogens, including those resistant to conventional antibiotic therapy. ${ }^{19}$

In our study, the antimicrobial properties of magnetic nanoparticles functionalized by the well-known antiseptic, CHX, were thoroughly analyzed. CHX is a biguanide derivative and, due to both hydrophilic amine groups and hydrophobic structure, causes disruptions to membrane permeability at low doses. This is additionally facilitated by the positive charge of $\mathrm{CHX}$, which allows for binding of antimicrobial agents to anionic molecules present on the pathogen cell wall. ${ }^{1}$ Importantly, it has been shown that this phenomenon is more likely than the inhibition of cell membrane ATPases and that destabilization of pathogen membranes is the lethal event in the $\mathrm{CHX}$ mechanism of action. ${ }^{40}$ At higher concentrations, $\mathrm{CHX}$ attacks the bacterial cytoplasmic membrane and denatures microbial proteins. CHX has both a rapid onset of bactericidal action and prolonged antimicrobial efficacy through residual effects. ${ }^{1}$ It is established that CHX possess broad spectrum of activity against Gram-positive and Gram-negative bacteria and fungi. However, in that case, interestingly, Barrett-Bee et al demonstrated the treatment of Gram-negative bacteria with $\mathrm{CHX}$ leads to the release of periplasmic enzymes, but not the disruption of inner membranes. ${ }^{41}$ Moreover, Audus et al showed that CHX strongly inhibits adherence of C. albicans to human buccal epithelial cells and altered epithelial-cell membrane-lipid packing order, which is likely involved in the antifungal actions of the drug. ${ }^{42}$ According to the data shown here, immobilization of $\mathrm{CHX}$ on magnetic nanocarriers modulates its mechanism of action, resulting in depolarization 

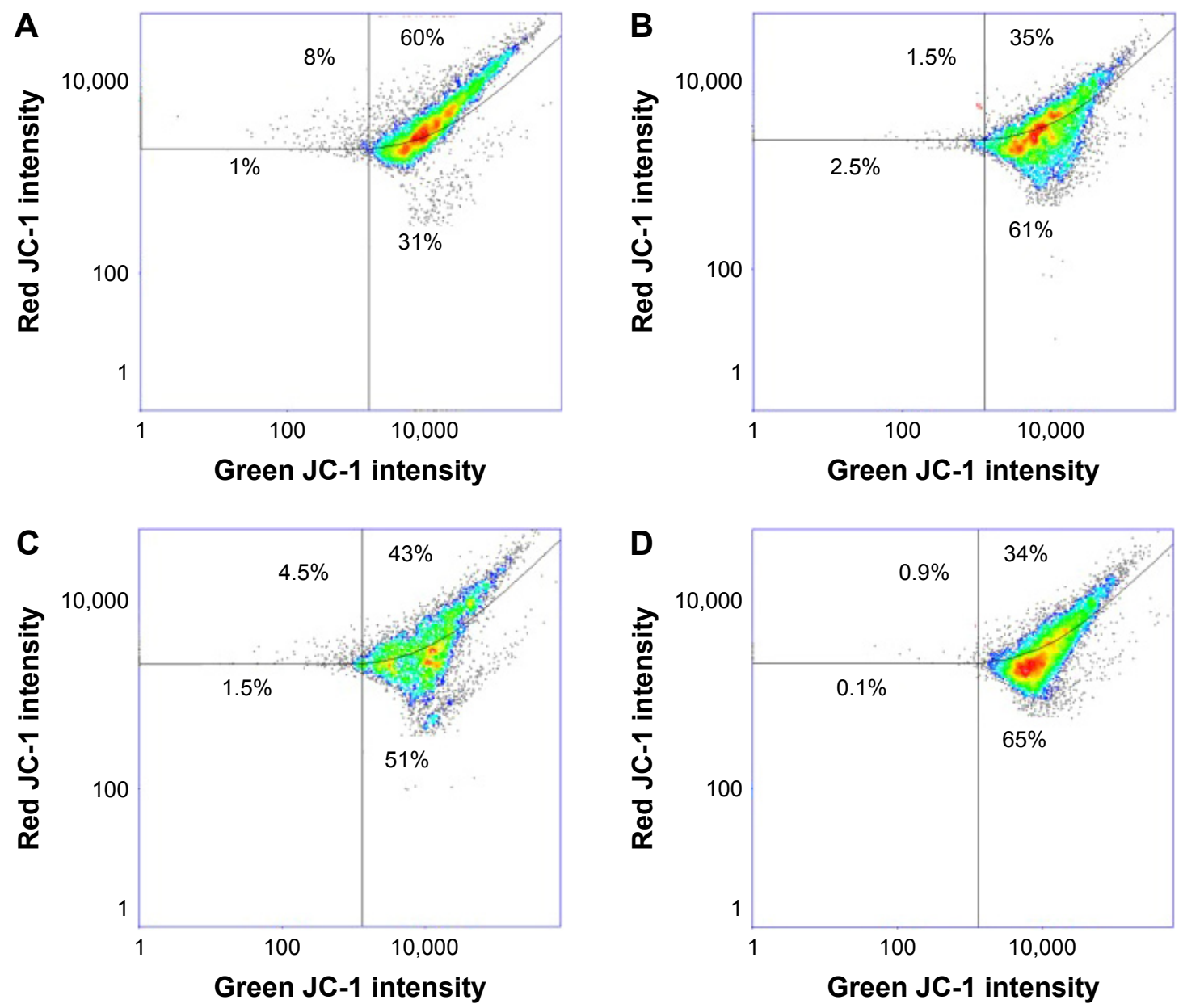

Figure 5 Magnetic nanoparticles induce oxidative stress in Candida cells.

Notes: Flow cytometry analysis of the oxidative damage of untreated $(\mathbf{A})$ and treated by $3 \% \mathrm{H}_{2} \mathrm{O}_{2}(\mathbf{B})$ Candida albicans cells compared to cells treated by $10 \mu \mathrm{gg} / \mathrm{mL}$ chlorhexidine (C) and chlorhexidine-coated magnetic nanoparticles (D) after 30 min incubation.
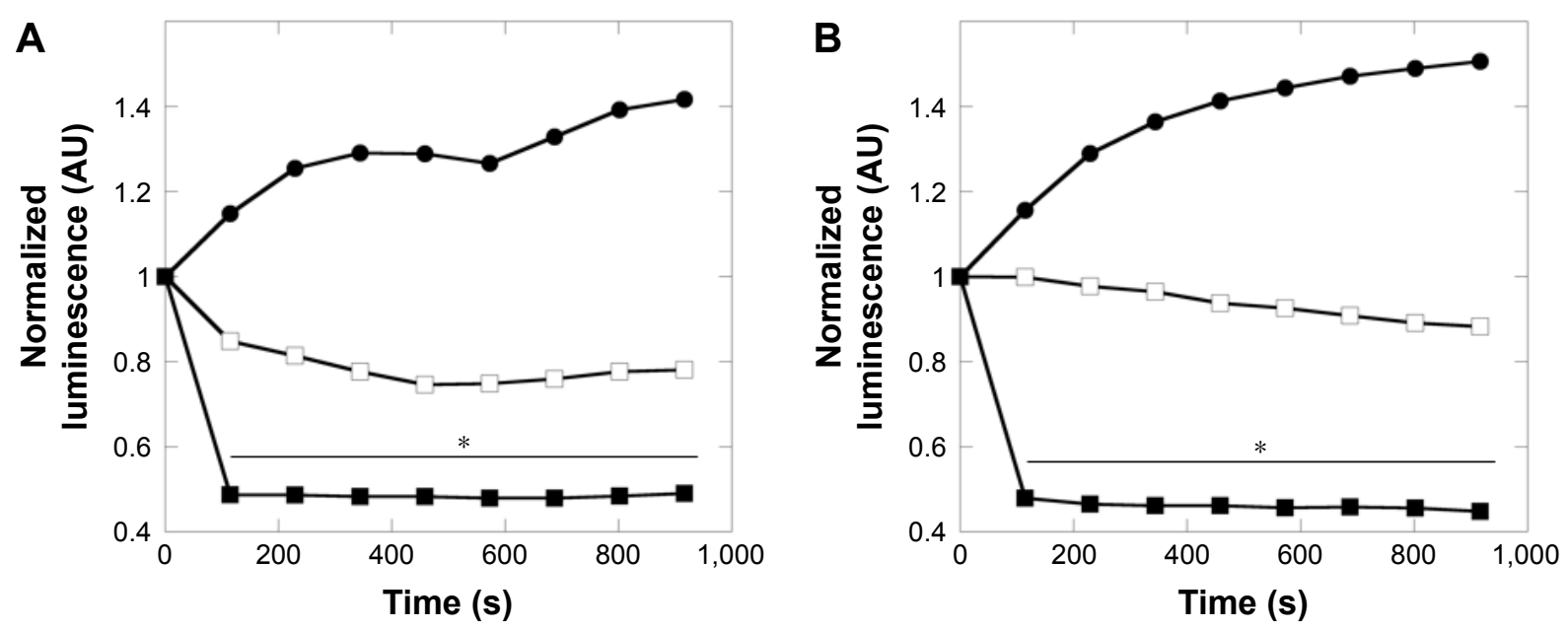

$\longrightarrow \mathrm{CT} \longrightarrow \mathrm{CHX} \longrightarrow-\mathrm{MNP} @ \mathrm{CHX}$

Figure 6 Magnetic nanoparticles accelerate chlorhexidine antibacterial action.

Notes: Reduction of Pseudomonas aeruginosa Xen 5 chemiluminescence signal after addition of chlorhexidine in free and immobilized forms (A) and in the presence of human saliva (B). *Statistically significant $(P<0.05)$ compared to $\mathrm{CHX}$ in free form.

Abbreviations: $\mathrm{CHX}$, chlorhexidine; $\mathrm{CT}$, untreated control; MNP@CHX, magnetic nanoparticles functionalized by chlorhexidine. 

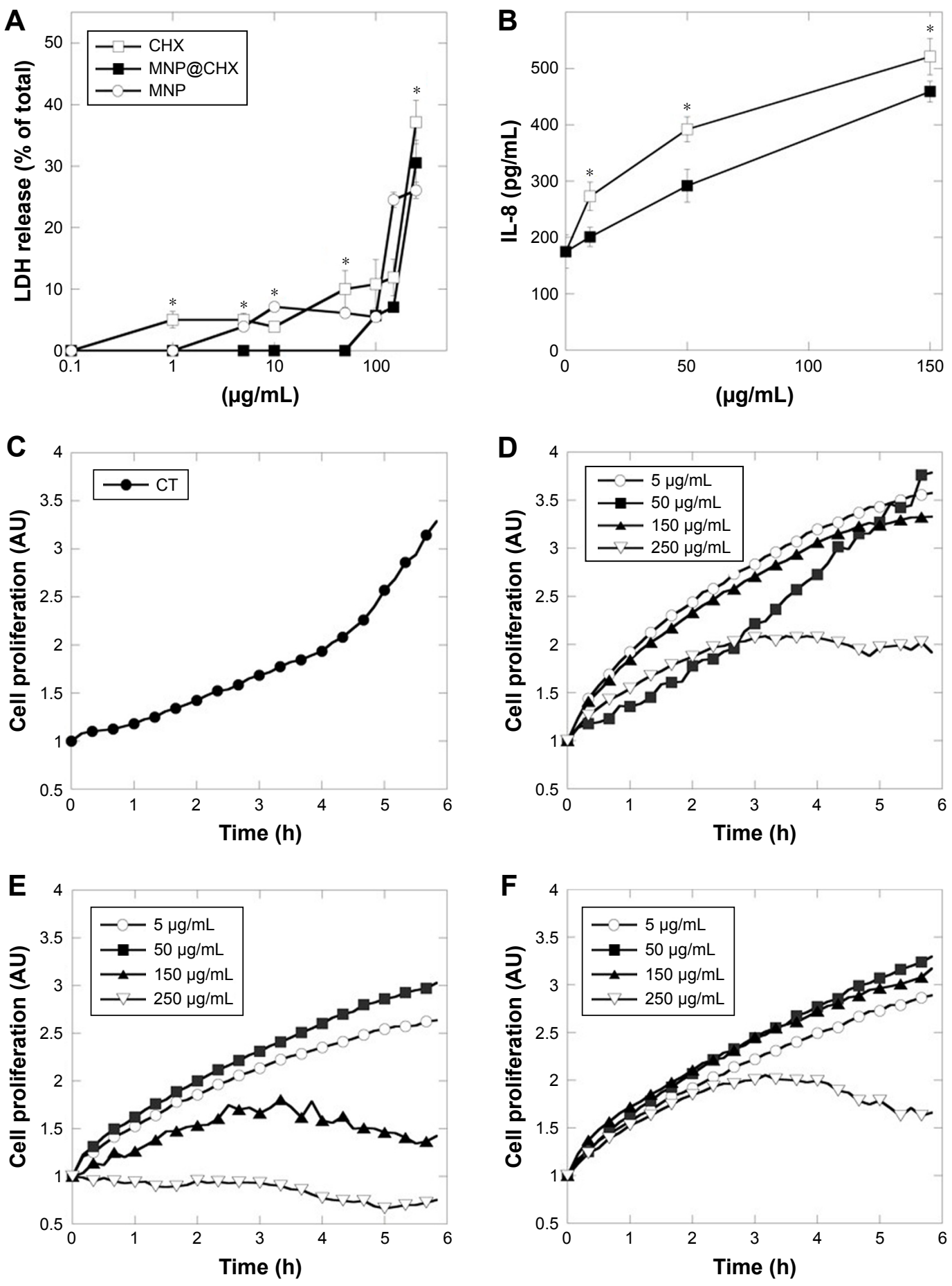

Figure 7 Effect of chlorhexidine in free and immobilized forms on human osteoblast cell integrity, interleukin release and their growth.

Notes: Panels (A, B) show the release of LDH and IL-8 from human osteoblast after $24 \mathrm{~h}$ of treatment. The growth curves of untreated osteoblast cells (C) and after addition of magnetic nanoparticles (D), chlorhexidine (E) and MNP@CHX (F) from 5 to $250 \mu \mathrm{g} / \mathrm{mL}$. *Statistically significant $(P<0.05)$ compared to $\mathrm{CHX}$ in immobilized form. Abbreviations: CHX, chlorhexidine; CT, untreated control; MNP@CHX, magnetic nanoparticles functionalized by chlorhexidine.

of mitochondria in treated fungal cells. Taken together, we propose that induction of oxidative stress and oxidation of fungal structures are additional mechanisms responsible for pathogen killing in the presence of MNP@CHX.
Development of modern dentistry using nanotechnology approaches is focusing on esthetics by making the materials more translucent, modify the wear properties as well as prevent rather than treat biofilm-dependent oral diseases 
including formation of dental caries and endodontic and periodontal diseases. ${ }^{43}$ To data, several nanomaterials such as metallic (silver, zinc oxide) and polymeric (mesoporous silica, polyethylenimine) have been used for dental composite or dental adhesive creation to inhibit pathogen growth. This is due to the generation of reactive oxygen species, disruption of the cell membrane, inhibition metabolic processes, displacement of magnesium ions required for the enzymatic activity of oral biofilms, disturbance of the electron transportation, oxidation of macromolecules and prevention of DNA replication. ${ }^{44}$ These nanoparticles are able to reduce the bacterial dental plaque biofilm formation in an in vitro setting. ${ }^{45}$ It has also been shown that coating teeth with antibacterial nanomaterials is effective in restricting bacteria growth as well as inhibiting bacterial adhesion and preserving its integrity in the presence of saliva. ${ }^{46}$ In our study, we report, for the first time, the enhanced activity of CHX-functionalized magnetic nanoparticles against Candida sp. which are the most common opportunistic pathogens in oral microbiota and play a key role in failure of root canal treatment. ${ }^{47,48}$ We have also shown that our nanosystem is able to restrict the growth of pathogens in monomicrobial and polymicrobial conditions. Broad spectrum activity that includes activity against Gram-positive and Gram-negative bacteria and fungi is important because mixed infections are common in oral cavity causing topical and postsurgery infections. ${ }^{49}$ Moreover, significant reduction of fungal biofilm growth and prevention before penetration into dental filling has been observed. Importantly, in agreement with previous reports, we confirmed that magnetic derivatives of CHX not only maintained the antimicrobial activity of $\mathrm{CHX}$ but also increased its killing properties in the presence of saliva. This observation is significant as previous reports demonstrate reduced antimicrobial activity of $\mathrm{CHX}$ against oral bacteria in human saliva. ${ }^{50,51}$ The neutralizing effect of saliva on CHX may be overcome by the addition of $7 \%$ ethanol due to its antimicrobial effect and its impact on salivary proteins. ${ }^{50}$ Despite the desirable synergistic effect of ethanol on the antimicrobial activity of $\mathrm{CHX}$, some reports indicate that the addition of this compound into mouth rinse formulations might be associated with the development of oral cancer due to DNA adduct formation and sister chromatid exchange in vitro. ${ }^{52}$ However, more recent research suggests that the protumorigenic effect of ethanol is observed if concentrations above $25 \%$ are used..$^{53}$ The attachment of $\mathrm{CHX}$ onto magnetic nanoparticles considerably enhances the activity of $\mathrm{CHX}$ in human saliva and offers an alternative for ethanol in mouth rinse formulations. Importantly, this effect is not associated with the toxic effects initially observed for unmodified $\mathrm{CHX}$.
A number of studies confirm the cytotoxic effect of $\mathrm{CHX}$ on the viability of host cells. Balloni et al showed that $\mathrm{CHX}$ containing mouth rinses reduce fibroblast and keratinocyte adhesion and considerably affects cell proliferation due to downregulation of cell adhesion receptors and altered gene expression of matrix components. ${ }^{54} \mathrm{CHX}$ is also considered as the one of the most cytotoxic of the commonly used root canal irrigants. ${ }^{55}$ Among other intracanal irritants, more toxic agents such as sodium hypochlorite might be distinguished. ${ }^{56,57}$ In contrast, CHX does not affect significantly the viability of murine macrophages, but may have an immunosuppressive effect on exposed macrophages. ${ }^{58}$ A recent study demonstrated that cytotoxicity of $\mathrm{CHX}$ might be reduced using modified nonequilibrium plasma. Considering these data, plasma-based modification was proposed as a safe option for root canal treatment. ${ }^{59}$ Data presented in this study confirmed that immobilization of CHX on MNPs also decreases the toxic effect of $\mathrm{CHX}$ without affecting its killing properties. In effect, magnetic derivatives of $\mathrm{CHX}$ may be an interesting alternative for formulations presented by Chen et al. ${ }^{60}$ Importantly, the employment of nanotechnology-based structures in dentistry provides a way for the introduction of novel therapy approaches based on structures that allow to control drug release and to improve the regenerative processes with subsequent strong antimicrobial activity, even in the presence of salivary proteins. ${ }^{61}$

\section{Conclusion}

MNPs functionalized by $\mathrm{CHX}$ represent a novel approach for the therapy of oral pathogens. Due to the strong antimicrobial activity of magnetic derivatives, the proposed formulation is effective in the treatment of monomicrobial as well as polymicrobial infections, which is additionally intensified by the strong anti-biofilm activity of this derivative. Essentially, the enhanced killing activity of MNP@CHX in the presence of salivary proteins coupled with its low toxicity against human osteoblasts strongly indicates the potential use of this formulation in the treatment of local infections caused by oral microflora.

\section{Acknowledgments}

This work was supported by the National Science Center, Poland, under grant UMO-2014/15/D/NZ6/02665 (to KN). In 2016, KN was awarded a fellowship from the Foundation for Polish Science. This study was conducted with the use of equipment purchased by the Medical University of Białystok as part of the RPOWP 2007-2013 funding, Priority I, Axis 1.1, contract number UDA-RPPD.01.01.00-20-001/ 15-00, dated 26.06.2015. 


\section{Disclosure}

The authors report no conflicts of interest in this work.

\section{References}

1. Karpiński TM, Szkaradkiewicz AK. Chlorhexidine - pharmacobiological activity and application. Eur Rev Med Pharmacol Sci. 2015; 19(7):1321-1326.

2. Wood A, Payne D. The action of three antiseptics/disinfectants against enveloped and non-enveloped viruses. J Hosp Infect. 1998;38(4): 283-295.

3. Fathilah AR, Himratul-Aznita WH, Fatheen AR, Suriani KR. The antifungal properties of chlorhexidine digluconate and cetylpyrinidinium chloride on oral Candida. J Dent. 2012;40(7):609-615.

4. Kuyyakanond T, Quesnel LB. The mechanism of action of chlorhexidine. FEMS Microbiol Lett. 1992;100(1-3):211-215.

5. Zorko M, Jerala R. Alexidine and chlorhexidine bind to lipopolysaccharide and lipoteichoic acid and prevent cell activation by antibiotics. J Antimicrob Chemother. 2008;62(4):730-737.

6. Bonacorsi C, Raddi MS, Carlos IZ. Cytotoxicity of chlorhexidine digluconate to murine macrophages and its effect on hydrogen peroxide and nitric oxide induction. Braz J Med Biol Res. 2004;37(2):207-212.

7. Mimoz O, Lucet JC, Kerforne T, et al. Skin antisepsis with chlorhexidine-alcohol versus povidone iodine-alcohol, with and without skin scrubbing, for prevention of intravascular-catheter-related infection (CLEAN): an open-label, multicentre, randomised, controlled, twoby-two factorial trial. Lancet. 2015;386(10008):2069-2077.

8. Coetzee E, Rode H, Kahn D. Pseudomonas aeruginosa burn wound infection in a dedicated paediatric burns unit. S Afr J Surg. 2013;51(2): 50-53.

9. Varoni E, Tarce M, Lodi G, Carrassi A. Chlorhexidine (CHX) in dentistry: state of the art. Minerva Stomatol. 2012;61(9):399-419.

10. Manikandan D, Balaji VR, Niazi TM, Rohini G, Karthikeyan B, Jesudoss P. Chlorhexidine varnish implemented treatment strategy for chronic periodontitis: a clinical and microbial study. J Pharm Bioallied Sci. 2016;8(Suppl 1):S133-S137.

11. Edmiston CE Jr, Bruden B, Rucinski MC, Henen C, Graham MB, Lewis BL. Reducing the risk of surgical site infections: does chlorhexidine gluconate provide a risk reduction benefit? Am J Infect Control. 2013;41(5 Suppl):S49-S55.

12. Miller LM, Loder JS, Hansbrough JF, Peterson HD, Monafo WW, Jordan MH. Patient tolerance study of topical chlorhexidine diphosphanilate: a new topical agent for burns. Burns. 1990;16(3):217-220.

13. Supranoto SC, Slot DE, Addy M, Van der Weijden GA. The effect of chlorhexidine dentifrice or gel versus chlorhexidine mouthwash on plaque, gingivitis, bleeding and tooth discoloration: a systematic review. Int J Dent Hyg. 2015;13(2):83-92.

14. Athanassiadis B, Abbott PV, Walsh LJ. The use of calcium hydroxide, antibiotics and biocides as antimicrobial medicaments in endodontics. Aust Dent J. 2007;52(1 Suppl):S64-S82.

15. McDonnell G, Russell AD. Antiseptics and disinfectants: activity, action, and resistance. Clin Microbiol Rev. 1999;12(1):147-179.

16. Brooks SE, Walczak MA, Hameed R, Coonan P. Chlorhexidine resistance in antibiotic-resistant bacteria isolated from the surfaces of dispensers of soap containing chlorhexidine. Infect Control Hosp Epidemiol. 2002;23(11):692-695.

17. Bhardwaj P, Ziegler E, Palmer KL. Chlorhexidine induces vanAtype vancomycin resistance genes in enterococci. Antimicrob Agents Chemother. 2016;60(4):2209-2221.

18. Liu Q, Zhao H, Han L, Shu W, Wu Q, Ni Y. Frequency of biocideresistant genes and susceptibility to chlorhexidine in high-level mupirocin-resistant, methicillin-resistant Staphylococcus aureus $(\mathrm{MuH}$ MRSA). Diagn Microbiol Infect Dis. 2015;82(4):278-283.

19. Huh AJ, Kwon YJ. "Nanoantibiotics": a new paradigm for treating infectious diseases using nanomaterials in the antibiotics resistant era. J Control Release. 2011;156(2):128-145.
20. Piktel E, Niemirowicz K, Wątek M, Wollny T, Deptuła P, Bucki R Recent insights in nanotechnology-based drugs and formulations designed for effective anti-cancer therapy. J Nanobiotechnology. 2016; 14(1):39.

21. Niemirowicz K, Prokop I, Wilczewska AZ, et al. Magnetic nanoparticles enhance the anticancer activity of cathelicidin LL-37 peptide against colon cancer cells. Int J Nanomedicine. 2015;10:3843-3853.

22. Niemirowicz K, Surel U, Wilczewska AZ, et al. Bactericidal activity and biocompatibility of ceragenin-coated magnetic nanoparticles. J Nanobiotechnology. 2015;13(1):32.

23. Michalak G, Gluszek K, Piktel E, et al. Polymeric nanoparticles - a novel solution for delivery of antimicrobial agents. Studia Medyczne. 2016;32(1):56-62.

24. Gu H, Ho PL, Tong E, Wang L, Xu B. Presenting vancomycin on nanoparticles to enhance antimicrobial activities. Nano Letters. 2003;3(9): 1261-1263.

25. Niemirowicz K, Markiewicz KH, Wilczewska AZ, Car H. Magnetic nanoparticles as new diagnostic tools in medicine. Adv Med Sci. 2012;57(2):196-207.

26. Niemirowicz K, Swiecicka I, Wilczewska AZ, et al. Growth arrest and rapid capture of select pathogens following magnetic nanoparticle treatment. Colloids Surf B Biointerfaces. 2015;131:29-38.

27. Park H, Park HJ, Kim JA, et al. Inactivation of Pseudomonas aeruginosa PA01 biofilms by hyperthermia using superparamagnetic nanoparticles. J Microbiol Methods. 2011;84(1):41-45.

28. Taylor E, Webster TJ. Reducing infections through nanotechnology and nanoparticles. Int J Nanomedicine. 2011;6:1463-1473.

29. Niemirowicz K, Durnaś B, Tokajuk G, et al. Magnetic nanoparticles as a drug delivery system that enhance fungicidal activity of polyene antibiotics. Nanomedicine. 2016;12(8):2395-2404.

30. Massart R. Preparation of aqueous magnetic liquids in alkaline and acidic media. IEEE Transactions on Magnetics. 1981;17(2):1247-1248.

31. Niemirowicz K, Swiecicka I, Wilczewska AZ, et al. Gold-functionalized magnetic nanoparticles restrict growth of Pseudomonas aeruginosa. Int J Nanomedicine. 2014;9:2217-2224.

32. MisztalewskaI,WilczewskaAZ,WojtasikO,MarkiewiczKH,KuchlewskiP, Majcher AM. New acetylacetone-polymer modified nanoparticles as magnetically separable complexing agents. RSC Advances. 2015;5(121):100281-100289.

33. Meletiadis J, Mouton JW, Meis JF, et al. Comparison of spectrophotometric and visual readings of NCCLS method and evaluation of a colorimetric method based on reduction of a soluble tetrazolium salt, 2,3-bis [2-methoxy-4-nitro-5-[(sulfenylamino) carbonyl]-2Htetrazolium-hydroxide], for antifungal susceptibility testing of Aspergillus species. J Clin Microbiol. 2001;39(12):4256-4263.

34. Sabaeifard P, Abdi-Ali A, Soudi MR, Dinarvand R. Optimization of tetrazolium salt assay for Pseudomonas aeruginosa biofilm using microtiter plate method. J Microbiol Methods. 2014;105:134-140.

35. O'Toole GA. Microtiter dish biofilm formation assay. J Vis Exp. 2011;(47):pii 2437.

36. Hussein-Al-Ali SH, El Zowalaty ME, Hussein MZ, Ismail M, Webster TJ. Synthesis, characterization, controlled release, and antibacterial studies of a novel streptomycin chitosan magnetic nanoantibiotic. Int J Nanomed. 2014;9:549-557.

37. Niemirowicz K, Piktel E, Wilczewska AZ, et al. Core-shell magnetic nanoparticles display synergistic antibacterial effects against Pseudomonas aeruginosa and Staphylococcus aureus when combined with cathelicidin LL-37 or selected ceragenins. Int $J$ Nanomedicine. 2016;11:5443-5455.

38. Bucki R, Niemirowicz K, Wnorowska U, et al. Polyelectrolyte-mediated increase of biofilm mass formation. BMC Microbiol. 2015;15:117.

39. Wnorowska U, Wątek M, Durnaś B, et al. Extracellular DNA as an essential component and therapeutic target of microbial biofilm. Studia Medyczne. 2015;31(2):132-138.

40. Nguyen TK, Duong HTT, Selvanayagam R, Boyer C, Barraud N. Iron oxide nanoparticle-mediated hyperthermia stimulates dispersal in bacterial biofilms and enhances antibiotic efficacy. Sci Rep. 2015;5:18385. 
41. Barrett-Bee K, Newboult L, Edwards S. The membrane destabilising action of the antibacterial agent chlorhexidine. FEMS Microbiol Lett. 1994;119(1-2):249-253.

42. Audus KL, Tavakoli-Saberi MR, Zheng H, Boyce EN. Chlorhexidine effects on membrane lipid domains of human buccal epithelial cells. J Dent Res. 1992;71(6):1298-1303.

43. Mantri SS, Mantri SP. The nano era in dentistry. J Nat Sci Biol Med. 2013;4(1):39-44.

44. Abou Neel EA, Bozec L, Perez RA, Kim HW, Knowles JC. Nanotechnology in dentistry: prevention, diagnosis, and therapy. Int $J$ Nanomedicine. 2015;10:6371-6394.

45. Li F, Weir MD, Fouad AF, Xu HH. Effect of salivary pellicle on antibacterial activity of novel antibacterial dental adhesives using a dental plaque microcosm biofilm model. Dent Mater. 2014;30(2):182-191.

46. Besinis A, De Peralta T, Handy RD. Inhibition of biofilm formation and antibacterial properties of a silver nano-coating on human dentine. Nanotoxicology. 2014;8(7):745-754.

47. Siqueira JF, Sen BH. Fungi in endodontic infections. Oral Surg Oral Med Oral Pathol Oral Radiol Endod. 2004;97(5):632-641.

48. Gomes C, Fidel S, Fidel R, de Moura Sarquis MI. Isolation and taxonomy of filamentous fungi in endodontic infections. $J$ Endod. 2010; 36(4):626-629.

49. O’Donnell LE, Millhouse E, Sherry L, et al. Polymicrobial Candida biofilms: friends and foe in the oral cavity. FEMS Yeast Res. 2015;15(7).

50. Amenabar I, Poly S, Nuansing W, et al. Structural analysis and mapping of individual protein complexes by infrared nanospectroscopy. Nat Commun. 2013;4:2890.

51. Shi YB, Liu L, Shao W, Wei T, Lin GM. Microcalorimetry studies of the antimicrobial actions of alkaloids. J Zhejiang Univ Sci B. 2015; 16(8):690-695.
52. Miyake Y, Tsunoda T, Minagi S, Akagawa Y, Tsuru H, Suginaka H. Antifungal drugs affect adherence of Candida albicans to acrylic surfaces by changing the zeta-potential of fungal cells. FEMS Microbiol Lett. 1990;57(3):211-214.

53. Sardi JC, Scorzoni L, Bernardi T, Fusco-Almeida AM, Mendes Giannini MJ. Candida species: current epidemiology, pathogenicity, biofilm formation, natural antifungal products and new therapeutic options. J Med Microbiol. 2013;62(Pt 1):10-24.

54. Balloni S, Locci P, Lumare A, Marinucci L. Cytotoxicity of three commercial mouthrinses on extracellular matrix metabolism and human gingival cell behaviour. Toxicol In Vitro. 2016;34:88-96.

55. Poletaev A, Boura P. The immune system, natural autoantibodies and general homeostasis in health and disease. Hippokratia. 2011;15(4): 295-298.

56. Wong DT, Cheung GS. Extension of bactericidal effect of sodium hypochlorite into dentinal tubules. J Endod. 2014;40(6):825-829.

57. Peck BW, Workeneh B, Kadikoy H, Abdellatif A. Sodium hypochloriteinduced acute kidney injury. Saudi J Kidney Dis Transpl. 2014;25(2): 381-384.

58. Cavaleiro E, Duarte AS, Esteves AC, et al. Novel linear polymers able to inhibit bacterial quorum sensing. Macromol Biosci. 2015;15(5): 647-656.

59. Guégan S, Lanternier F, Rouzaud C, Dupin N, Lortholary O. Fungal skin and soft tissue infections. Curr Opin Infect Dis. 2016;29(2):124-130.

60. Chen H, Shi Q, Qing Y, Yao YC, Cao YG. Cytotoxicity of modified nonequilibrium plasma with chlorhexidine digluconate on primary cultured human gingival fibroblasts. J Huazhong Univ Sci Technolog Med Sci. 2016;36(1):137-141.

61. Wang B, Wei P, Wang X, Lou W. Controlled synthesis and sizedependent thermal conductivity of $\mathrm{Fe}_{3} \mathrm{O}_{4}$ magnetic nanofluids. Dalton Trans. 2012;41(3):896-899.
International Journal of Nanomedicine

\section{Publish your work in this journal}

The International Journal of Nanomedicine is an international, peerreviewed journal focusing on the application of nanotechnology in diagnostics, therapeutics, and drug delivery systems throughout the biomedical field. This journal is indexed on PubMed Central, MedLine, CAS, SciSearch ${ }^{\circledR}$, Current Contents ${ }^{\circledR} /$ Clinical Medicine,

\section{Dovepress}

Journal Citation Reports/Science Edition, EMBase, Scopus and the Elsevier Bibliographic databases. The manuscript management system is completely online and includes a very quick and fair peer-review system, which is all easy to use. Visit http://www.dovepress.com/ testimonials.php to read real quotes from published authors. 